\title{
Os músicos e seus manuscritos
}

\author{
Mary Angela Biason (Museu da Inconfidência, Ouro Preto) \\ mary-biason@uol.com.br
}

Resumo: este artigo apresenta algumas considerações sobre o estudo dos documentos musicais a partir de seus suportes físicos, ferramentas utilizadas em sua confecção, a problemática do autógrafo na sucessão de cópias e suas trajetórias até serem incorporados aos nossos arquivos.

Palavras-chave: musicologia, acervos de documentos musicais, crítica genética, autógrafo musical.

\section{Musicians and their manuscripts}

Abstract: This article proposes some considerations on the study of musical documents, departing from its physical supports, tools used for its making process, the question of the autograph, copies and their trajectories until they finally become part of our archives.

Keywords: musicology, collections of musical documents, genetic criticism, musical autographs.

\section{1 - Introdução}

Em arquivos nos quais existe a preocupação em não descontextualizar os documentos musicais de sua gênese mais abrangente, registros detalhados de como a incorporação se deu nos fornecem variados subsídios para a análise. Mas, no tocante ao estudo mais individualizado de determinada produção musical nos faltam elementos para inferir com precisão o que cada músico legou. Detalhes sobre o uso desses papéis não costumavam ser anotados pelos músicos e raramente constavam em espólios testamentários. Essa lacuna de informação restringe nossos conhecimentos sobre a origem e trajetória desses acervos. Muitas vezes o significado dessa relação pessoal entre o músico e sua produção se perde em meio a hipóteses.

Desde a chegada em terras americanas das naus vindas da Europa e as conseqüentes celebrações que procuravam teatralizar a conquista daquele "Novo Mundo" estava presente a execução e produção musical como parte da liturgia católica. Conforme a administração portuguesa fincava mais os pés em solo americano, a música necessária para enobrecer e "civilizar" a vida social na Colônia tomava maior vulto. Os indícios dessa prática pululam na documentação administrativa e eclesiástica. ${ }^{1}$ Sobre o que teria sido aquela prática existem indícios em correspondências endereçadas a Portugal requisitando repertório novo. ${ }^{2}$ Mas os documentos musicais possuiam uma relação simbiótica com seus executores - só tinham valor na mão de músicos - e esse caráter pessoal determinou destinos diversos para as partes musicais que conseguiram sobreviver e chegar aos nossos dias. As músicas atendiam a escolhas pessoais e podiam ser guardadas ou descartadas de acordo com a mudança de gosto, função social ou esquema de trabalho.

Os documentos musicais produzidos na América Portuguesa que resistiram estão distribuidos hoje de maneira desigual. Praticamente não conhecemos documentos dos séculos XVI e XVII e os datados na primeira metade do século XVIII são poucos, somente no último quartel desse século é que a documentação começa a ser numerosa. Os papéis referentes ao século XIX formam um corpus mais coeso e de certa maneira este estado de coisas se repete nos diversos acervos já catalogados. As práticas culturais e sociais sobre a transmissão dos manuscritos em épocas passadas podem ajudar a explicar esse quadro. 0 caráter efêmero dos registros musicais em papel obviamente causou 0 desaparecimento dos manuscritos autógrafos restando as cópias, e seu estudo diz muito do seu uso, mas pouco de seu criador.

No Brasil, a maior parte dos estudos que utilizaram o documento musical, fosse manuscrito ou impresso, resumiu sua análise a aspectos estilísticos da obra. ${ }^{3}$ Contudo, outro universo de estudo tende a abrir-se quando a atenção da pesquisa se volta para o suporte de escrita e a todas as informações que dele podem advir. 0 papel, a marca d'água, a tinta, o instrumento de escrita, carimbos, 
textos, dedicatórias e as marcas de uso revelam muito sobre as pessoas que produziram, possuiram e utilizaram o material. Pode ser muito cedo para se escrever uma história definitiva sobre o músico e seus papéis, todavia, é possivel fazer algumas indicações preliminares.

A pesquisa sobre determinado compositor nunca deverá se ater somente aos aspectos mais superficiais de sua vida nem tampouco a aquilo que esteja diretamente ligado a sua atividade musical. Parcialidades costumam induzir ao erro e o músico ou a obra devem ser estudados em um contexto histórico largo. Cartas, ações cíveis, testamentos e outras notícias contemporâneas ao objeto de estudo enriquecem a composição de um quadro abrangente e mais fiel ao que teria significado escrever determinada peça musical. Contextualização, ou seja, embeber a análise do objeto das condicionantes extramusicais permite compreender as razões que resultaram na salvaguarda ou descarte de determinado manuscrito.

Outra ferramenta de pesquisa utilizada é chamada crítica genética cujo objeto de estudo é o próprio processo de criação musical a partir dos manuscritos ou documentos preparatórios. A crítica genética foi usada primeiramente nos estudos literários que visavam entender seus processos de criação:4 ao nos apropriarmos dessa ferramenta e transpondo-a para a análise musicológica seguimos os mesmos caminhos só que mirados no processo de criação musical. ${ }^{5}$

\section{2 - $\mathbf{0}$ sentido de autor e a crítica textual}

Antes da invenção da imprensa alargar o horizonte alcançado por uma obra, o livro manuscrito era o único meio de difusão da cultura escrita. Ateliês de copistas faziam reproduções a partir do autógrafo e as imperfeições e alterações cometidas nesse processo se perpetuavam como se do autor proviessem. Preocupado com esse tipo de intervenção, o escritor italiano Francesco Petrarca (1304-1374) dispensou o serviço dos copistas e fez do manuscrito autógrafo o único texto autêntico. Este ideal percorreu os séculos XIV e XV e ganhou adeptos como Christine de Pizan (1364-1430) e Charles d'Orleans (1394-1465), que, preocupados com o sentido de autoridade, também procuraram dar unidade às suas obras através do livro manuscrito. Após a Idade Média, a história da conservação dos autógrafos é também a história do reconhecimento do autor, culminando com a época romântica e a consagração de tudo o que carregava a marca de sua mão.

Após a edição do primeiro livro feito por Gutenberg, em 1455, ocorreu uma mudança no significado das palavras "autor" e "escritor". Autor passou a significar o livreiroimpressor que publicou a obra, ou seja, trouxe à luz de forma pública. 0 escritor seria aquele que escreveu um texto, independente se permanecesse manuscrito ou fosse publicado (FRAISSE, 2001, p.34). Somente no século XVII as línguas européias diferenciaram as palavras "escrita" e "impressa", atribuindo-Ihes significados diferentes. ${ }^{6}$ No século seguinte consolidou-se a definição de autor como aquele que criou a obra porque dela advém seu estilo, seus sentimentos, sua linguagem. A obra seria evidentemente transmitida pelos editores, mas sua realidade primeira seria legado do autor. Somente no final do século XIX todos os substratos produzidos até chegar à obra final (os manuscritos de trabalho, os rascunhos e de maneira geral, os "papéis" do autor), passam a ser considerados como uma classe específica de objetos fundamentais para a discussão da gênese do texto.

A Musicologia tem se beneficiado da crítica genética e dessa preocupação surgiram trabalhos focados na gênese da obra. ${ }^{7}$ Em manuscritos musicais brasileiros que conhecemos muito raramente encontramos estes testemunhos - dos primeiros esboços precoces aos últimos ajustes que consagrariam a obra acabada.

Em acervos nacionais catalogados existem alguns exemplos onde se pode estudar um compositor através de sua produção autógrafa. Neles o corpus documental autógrafo acompanha o músico nas várias fases de sua vida. São eles referentes a André da Silva Gomes (17521844, mestre-de-capela da Sé de São Paulo), ao Pe. José Maurício Nunes Garcia (1767-1830, músico da Capela Real de D. João VI no Rio de Janeiro), e a Antônio Carlos Gomes (1836-1896). Sobre este último, pode-se inclusive acompanhar sua caligrafia musical desde a infância, a partir da música que copiava para a orquestra de seu pai em Campinas.

Mas chamamos a atenção para o fato de que os esboços e "manuscritos de trabalho", que comporiam uma obra desde a gênese até sua conclusão, não encerram em si o caminho percorrido pela composição. As cópias manuscritas descoladas daquele ambiente gerador do original não podem ser menosprezadas. A apropriação de determinada obra pelos músicos subseqüentes e sua reutilização cria algo como um novo original e tal qual aquela célula mater também encerra informações preciosas. Nossa experiência na organização de acervos de documentos musicais, nomeadamente o acervo depositado no Museu da Inconfidência em Ouro Preto, nos levou a refletir sobre o universo da produção de cópias.

\section{3 - Assinatura e propriedade}

0 manuscrito musical mais cobiçado pelo musicólogo é o documento autógrafo porque ele traz o universo sonoro imaginado pelo autor. A identificação da caligrafia e da assinatura pode ser feita confrontando-se o documento musical com outros tipos de documentos onde o compositor escreveu ou assinou de próprio punho. Temos que advertir que a simples presença de uma assinatura não define autoria da obra; é necessário abstrair o impulso inicial de atribuição identificando os rastros sonoros do compositor para então corroborar ou não a autoria da obra.

Num acervo composto em sua maioria por cópias do original autógrafo, todos os nomes deixados nos documentos devem 


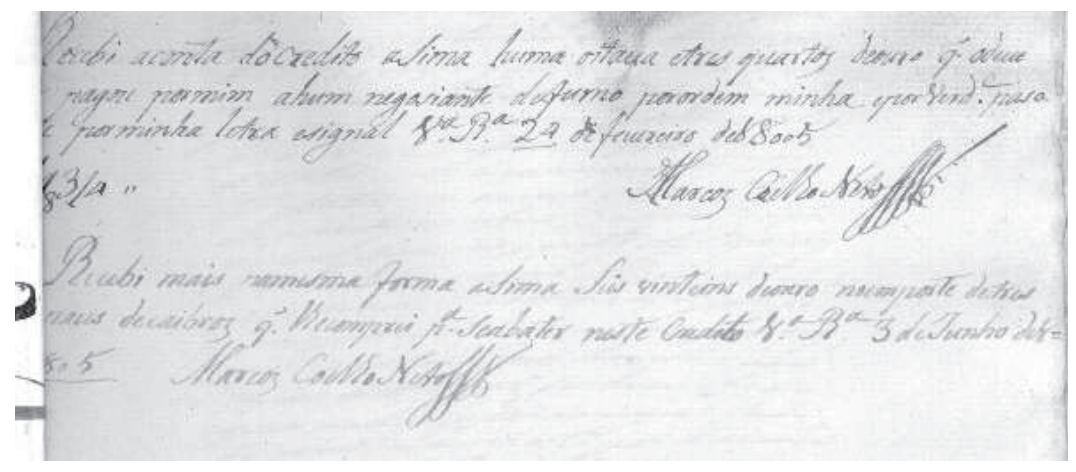

Fig.1 - Recibo de Marcos Coelho datado em 1805. Museu da Inconfidência - arquivo histórico.

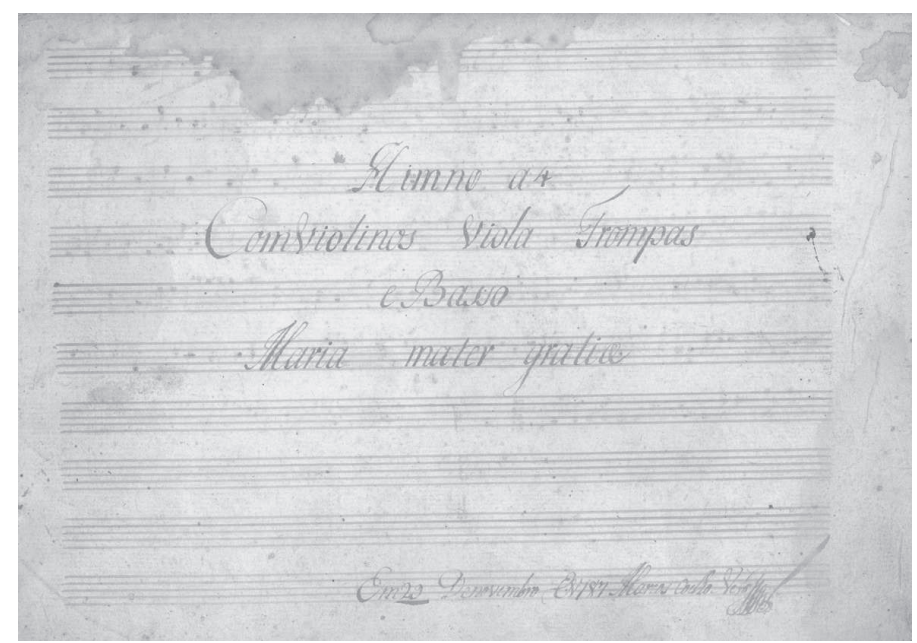

Fig.2 - Hino Maria Mater Gratiae. Autógrafo de Marcos Coelho Neto. MI-FCLange 036. Num acervo composto em sua maioria por cópias

ser levados em consideração, assim como qualquer menção da presença das pessoas que de alguma forma passaram a interferir na obra - possuindo, doando, executando etc. A assinatura, elemento definidor por excelência, pode indicar a propriedade do documento e a página de rosto de uma obra é o melhor local para estudar os processos de transferência de propriedade. Um exemplo existente no Museu da Inconfidência ilustra bem essa prática. Ele apresenta quatro proprietários nomeados e um incógnito, num recorte temporal que inicia na $1^{\text {a }}$ metade do século XIX, data provável da criação do documento, até 1890:

Título: "Credo a 4 Vozes / Com dois Viollinos / Trompas e Basso / Para uzo de / Liandro Lopes"

Segue: "Este Credo me foi dado pelo Professor de musica / o IIIm Snr João Antonio Pimenta / em $76 r^{\circ}$ de 1871"
Seque: "Hoje pertence a Lourenço Corra de Mello" Segue: "9bro 21 de 1890 / Pertence hoje ao Snr Ant ${ }^{\circ}$ Leão Lopes da Crúz / Por offerta de Lourenço Corrêa de Mello".8

Existe outro tipo de assinatura, que não é de próprio punho, mas idealizado pelo músico e por isso portador de sua marca. Trata-se dos carimbos de propriedade, muito comuns nos documentos do último quartel do século XIX. Os músicos carimbavam não apenas os papéis produzidos no seu tempo, mas todo tipo de papel de sua propriedade, inclusive os do século XVIII.

Tão importante quanto as assinaturas e os carimbos são os avisos e frases grafados pelos músicos, e que, de certo modo, também são indícios de apropriação daqueles que fizeram uso do documento. ${ }^{9}$ Os mais interessantes são os avisos de virada de página. Além do corriqueiro "Vire Presto" ou "WS" (Vire 


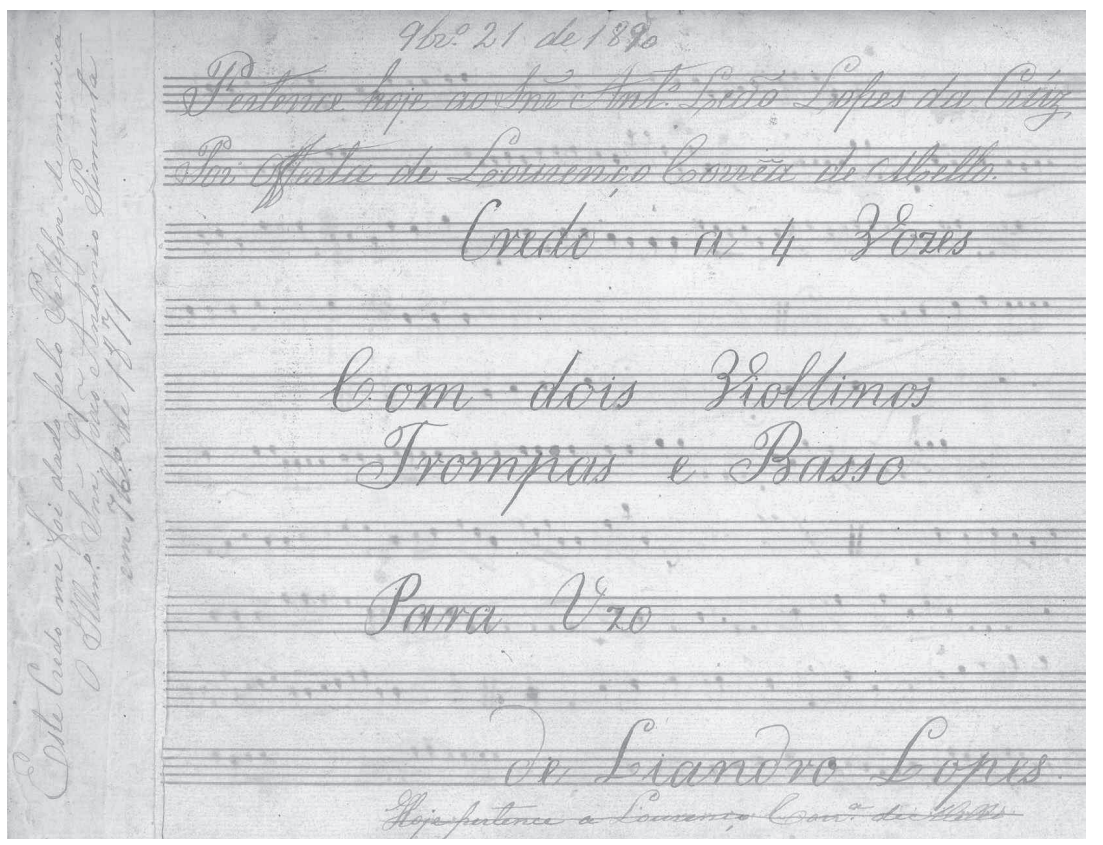

Fig.3 - Credo, página de rosto. MI-FCLange 409.

Vossa Senhoria), aparecem avisos dirigidos ao instrumentista: "Volte pa o Cum Sto Spiritus Snr Lopes". No documento podem ser encontrados lembretes de empréstimo da parte para estudo: "Trompa está com os meninos do Baptista"; indicação do copista: "Foi o Nhonhô do José Nunes quem copiou"; ou ainda o recado deixado por um admirador da solista: "Esta Ladainha é para D. Joaninha brilhar".

Alguns músicos relatam para qual ofício tocaram: "Faleceo um jovem na rua do Campo a honde / eu fui o músico e foi cepurtado na Sé / Ds a lembre de sua Alma". E outro, que deixou a interessante informação: "Esta Missa / Foi dado a os muzicos em refem de / fazer as Quinquenas no Amparo / Pella Sra Maria Cândida. ficarão / sendo dono desta Missa os que tocarem / na festa toda".

Esta última informação nos deu indícios sobre uma das práticas de transmissão de cópias. Ao cumprir a contento as determinações da festeira, os músicos poderiam ficar com as partes para si.

\section{4 - Do autógrafo para a cópia}

Autógrafos musicais são documentos fabulosos mas representam uma parcela muito pequena dos acervos. Cópias são os elementos que compõem a maioria dos documentos musicais, são cópias de uso, cópias para presente, cópias de iniciante, cópias de rascunho, cópias profissionais, cópias de instrumentista, cópias enviadas pelo correio, cópias feitas a duas e até a três mãos. Finalidades diversas, mas o motivo central, certamente, era o zelo pela transmissão e preservação do repertório.

A cópia traz uma prática muito próxima das operações que se pode encontrar em um autógrafo, pois ela poderá também projetar, escrever, corrigir, ratificar, reescrever, constituir uma forma que se adapte às suas necessidades, ou seja, transcrever o universo sonoro de outra pessoa, e ainda fazer algumas modificações próprias. Já o autógrafo é construído pelo autor, que controlou sua criação até a obra acabada, mesmo que ele tenha escrito outras versões desta mesma obra. A partir do momento em que cópias posteriores vão sendo feitas por outros músicos, ele já não controla a criação e seu autógrafo fica confinado a um grupo de músicos, ouvintes e discípulos.

Mas que significado pode ter o autógrafo no momento em que as cópias difundem não mais a construção sonora imaginada pelo autor, mas a do copista, além da facilidade da obra reproduzir-se indefinidamente? Um documento autógrafo é a expressão da vontade do autor, cópias fiéis ao autógrafo refletem o respeito do copista por aquele autor (no sentido de autoridade), cópias modificadas refletem não só a necessidade de instrumentação diferenciada da original devido a falta de instrumentos originais ou de quem os toque, como também uma mudança de função e uso da obra. Isso acontece em obras sacras quando partes de um ofício são excluídas ou reduzidas por mudanças na liturgia. Uma cópia pode ainda refletir a necessidade de mudança estrutural da obra por questão de gosto com inclusão de aberturas, intermezzi e finais instrumentais compostos pelo próprio copista, utilizando elementos da obra.

0 poder do músico e a unidade de sua escrita serão transgredidos de maneira radical, à custa das cópias. A ruptura entre o autógrafo e a cópia acontece quando 0 copista é capaz de fazer modificações na obra original, 


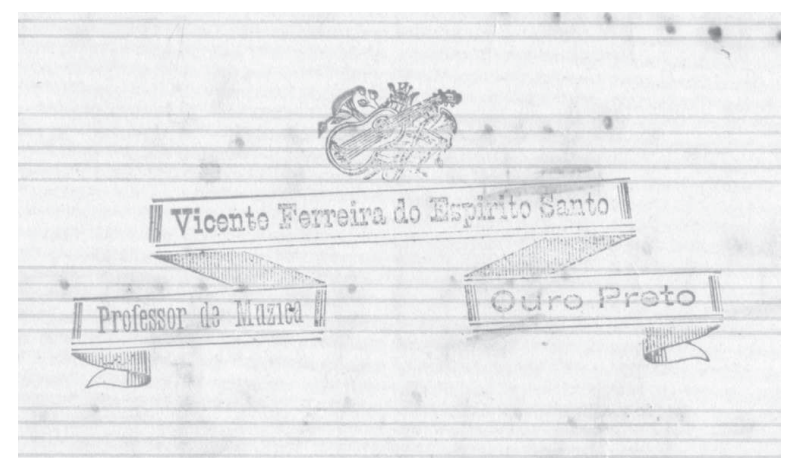

Fig.4 - Carimbo. MI-FCLange 069

o que confere um novo status ao autógrafo, que pode ser destruído e não mais participar de sua difusão, que será feita a partir dessas cópias. Dois domínios assim se formam: um que reúne e isola o autógrafo e outro no qual uma multidão se torna co-autora.

\section{5 - 0 papel de música}

0 conhecimento do objeto material é o melhor caminho para o conhecimento do objeto intelectual. As mudanças sucessivas no desenvolvimento tecnológico do conjunto de utensílios de escrita, ou seja, o papel, a pena e as tintas, fornecem subsídios importantes para a história desses documentos (GRÉSILLON, 1991, p.89).

Apesar do papel ter diversas aplicações, no século XVIII ele não representava um produto de preço acessivel a todos. $\mathrm{Na}$ Europa eram produzidos basicamente quatro tipos de papel: o oficial, para documentos administrativos, o papel próprio para impressão, o papel de escrita, que era mais fino e não tão branco como os anteriores, e o papel de uso geral, que por ser mais espesso prestava-se melhor para o desenho, pintura, confecção de cartas de jogar (baralhos), embalagens e para escrita musical. 0 motivo do uso de um papel mais espesso para notação musical se deve principalmente ao desgaste que as partituras sofriam na constante manipulação e porque a posse destas garantia a disponibilidade de repertório para a ocasião em que os músicos fossem solicitados. Porém, pode-se encontrar muita música escrita em papel comum e até em papel oficial usado nas repartições públicas, 0 que denota que, na sua escolha, são determinantes muitos outros fatores como distribuição, custo e disponibilidade do material. Temos que levar em consideração a importância da música a ser registrada e a ocasião para que fosse executada, porque estes fatores também podem influir na qualidade do papel a ser utilizado.

0 papel que chegava ao Brasil no periodo colonial era proveniente do comércio que Portugal mantinha com centros de produção europeus. Dessa compra, uma parte era destinada ao consumo interno, porque Portugal não possuía produção significativa, ${ }_{1}^{10}$ e 0 restante era revendido às colônias. Do século $\mathrm{XV}$ ao $\mathrm{XVII}$, Portugal comprou grande quantidade de papel francês e no século XVIII passou a comprar mais da Holanda e da Itália. Nos arquivos nacionais atuais encontramos muito papel espesso in folio dobrado, usado quase sempre no sentido horizontal. As folhas não vinham pautadas: as resmas eram compradas e com o rastrum, uma espécie de caneta de cinco penas, se desenhava a pauta. Olhando com cuidado um manuscrito dessa época, pode-se notar o vinco delimitando a margem esquerda e direita e, se prestarmos atenção nas extremidades da pauta, poderemos verificar um acúmulo de tinta no início da pauta e um certo desvio do rastrum no final. Somente no século XIX começa a aparecer a pauta impressa.

As marcas d'água encontradas nos documentos musicais do Museu da Inconfidência confirmam a procedência do papel: muitos são italianos, como os do papeleiro Giorgio Magnani e seus descendentes, e outros que apresentam o desenho de três luas crescentes. Estas duas marcas coincidem com as encontradas, por exemplo, no acervo de música do Palácio Nacional da Ajuda em Lisboa, mas existem muitos outros papeleiros representados no acervo do Inconfidência.

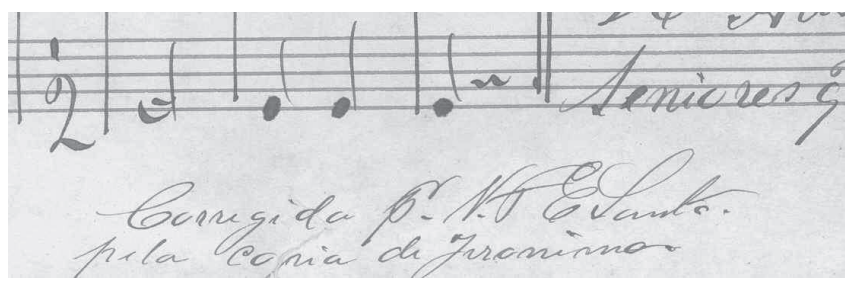

Fig.5 - Cópia de Vicente Ferreira do Espírito Santo do Ofício de 5ª Feira Santa de Jerônimo de Souza Lobo. MI-FCLange 200. 


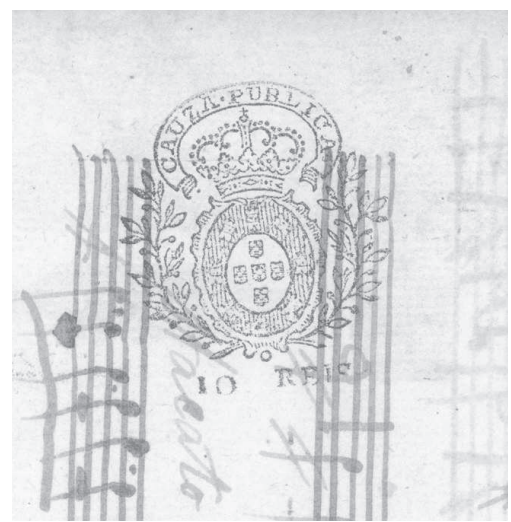

Fig.6 - Uso do papel oficial. Mi-FCLange 044.

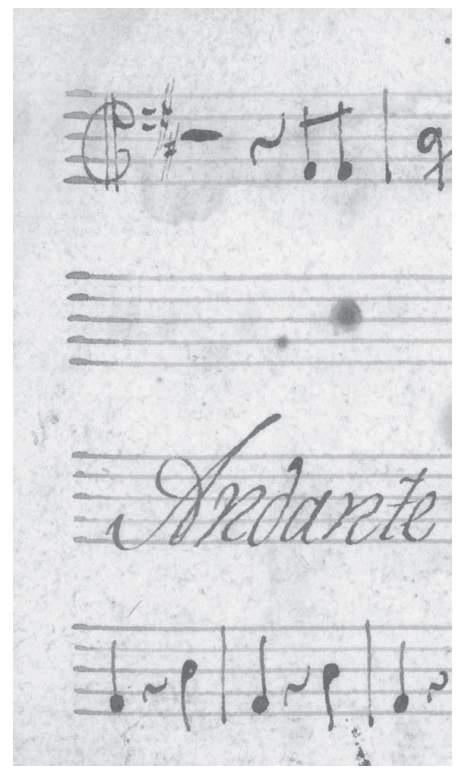

Fig.7 - Marca do rastrum. MI-FCLange 090.

Pesquisando outras marcas como o selo branco que aparece em documentos datados da segunda metade do século XIX, já se pode observar a existência das casas de comércio de artigos musicais brasileiras como as cariocas "Filippone \&t Arthur Napoleão" e "Irmãos Bevilacqua" e a paulista "Casas Levy". Também são encontrados papéis franceses "Lard \& Esnau" e "Gotrot Ainè".

\section{6 - Tipos de cópias e instrumentos de escrita} Existem dois modelos de cópia manuscrita: a profissional, chamada de copisteria musical, e a amadora, de uso corriqueiro, com alguns descuidos. A copisteria era formada basicamente por três profissionais: um para riscar a pauta, ou pautador, outro para desenhar as notas, ou apontador, o escrivão para escrever os textos, e em alguns casos, um quarto profissional para fazer as ornamentações. Todos juntos seguiam regras específicas para a legibilidade dos signos musicais e especial cuidado com as viradas de página para facilitar o trabalho do músico. Para tanto, era necessária uma análise do manuscrito do autor antes de dispor os compassos na folha. Já as cópias amadoras são mais despreocupadas, algumas com grafias feitas sem esmero, mas que não se afastam das convenções impostas para a leitura da notação musical.

Os instrumentos utilizados para a escrita com tinta foram as penas de aves e penas de metal. 0 uso da pena de ave para esse fim remonta à alta Idade Média e a maneira de talhá-la condiciona o modo de escrita. Instrumentos de escrita de metal são conhecidos desde a Antigüidade, mas vão efetivamente substituir as de aves a partir de 1830, quando o papel torna-se mais liso possibilitando o uso deste instrumento, enquanto que as penas de ave eram mais adaptadas a papéis vergados de produção manual. Em fins do século XIX aparecem as canetas tinteiro e no século XX as esferográficas.

Dois tipos de tinta são encontrados nos manuscritos: a de carbono, também conhecida como tinta da India, e a ferrogálica, feita a partir de uma combinação de sais de ferro. Esta última se acidifica com o tempo, desbotando de preto para marrom e "migrando" para outras folhas. Outro grande problema com a tinta ferrogálica é a corrosão do papel, acentuada pelo acúmulo de tinta nas notas musicais "cheias" (como semínimas e colcheias), causando o desaparecimento da nota, restando apenas um grande orifício no papel.

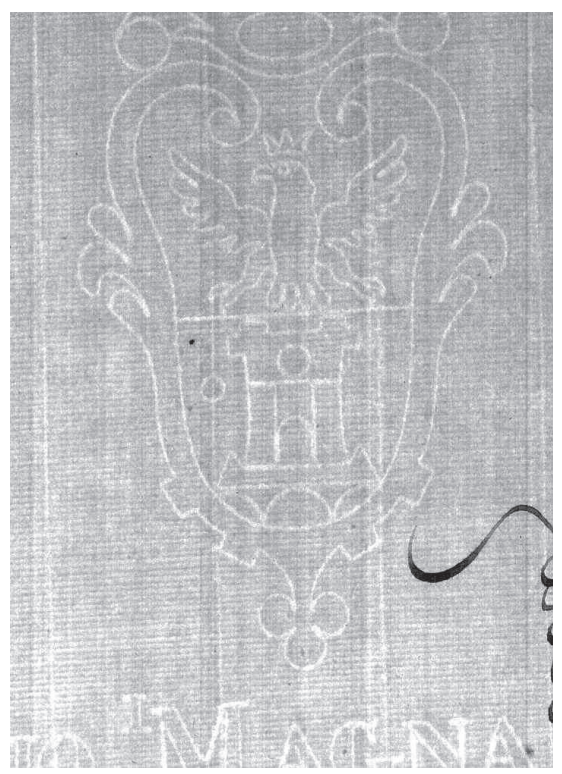

Fig.8 - Marca d'água Gior Magnani. MI-FCLange 014.

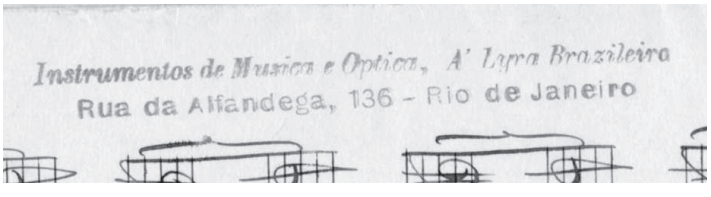

Fig.9 - Lyra Brasileira. MI-FCLange 240. 
Partindo do princípio que o documento musical deve ser definitivo e legível e que permanece na estante um pouco distante do instrumentista, é natural que seja escrito a tinta e não a lápis, cujos traços não penetram na superfície do papel podendo ser apagados. Os lápis existem desde o século XV e são encontrados nos documentos musicais brasileiros do século XVIII ao XX, utilizados para pequenas correções. As marcas a lápis, pela sua própria fragilidade material, não fornecem elementos suficientes, tanto quanto as tintas, para datar as intervenções. Neste caso temos que considerar o desenho das letras.

\section{7 - Conservação versus deterioração}

Os manuscritos nascem e envelhecem, mas uns envelhecem bem, outros mal, seja pelo uso, como vimos acima, seja pela qualidade do papel. Os papéis produzidos no século XVIII, principalmente aqueles vindos da Holanda, mesmo ainda em bom estado, sofrerão problemas de conservação por causa da introdução da pila holandesa"1 que, esfiapando demais os trapos, fazem com que as fibras de celulose fiquem mais curtas e mais vulneráveis aos ataques de fungos. Os papéis feitos a partir de outras fibras vegetais aparecem no mercado a partir de 1840, mas para seu desfibramento são utilizadas substâncias químicas aumentando sua acidez, tornando o papel quebradiço e amarelado, tal como hoje encontramos nos arquivos. Já os papéis do século XX são de qualidade muito inferior $e_{\text {, }}$ como hoje já começaram a amarelar, pode-se perguntar em que estado estarão daqui a um século.

Felizmente, o desenvolvimento tecnológico nos dá também os meios de remediar o mal feito. A utilização de técnicas básicas de conservação cria condições para a sobrevida do papel como embalar o documento com papel neutro a fim de evitar a transmissão da acidez e controlar a umidade e a temperatura do ambiente que abriga o acervo. Entretanto, um papel de má qualidade, mesmo que conservado dentro de todos os parâmetros ideais, se degradará de modo inevitável. Existe um método mais invasivo, o restauro, que pode desacidificar, matar fungos e branquear o papel por meio químico, mas trata-se de um processo lento e caro, aplicado somente em documentos muito especiais e em grande grau de degradação. Graças aos processos de microfilmagem, os manuscritos são facilmente acessiveis sem a necessidade da consulta ao original, este objeto insubstituivel.

\section{8 - Música impressa e música manuscrita}

No Brasil, a produção de papel e a criação de uma imprensa nacional ocorreram no início do século XIX após a vinda da família real e a música começaria a ser impressa por volta de 1840. 0 Brasil foi o país sulamericano que mais imprimiu música no século $X I X$ mas isto não significa que a partir daquele período 0 montante impresso ultrapassasse o manuscrito, pois 0 repertório é condicionado pelas vendas e pelo editor. 0 repertório impresso é direcionado mais às práticas domésticas, não para os músicos de corporações musicais que tocavam nas festividades populares e religiosas. Por vezes, os músicos não tinham condições de executar, por exemplo, a instrumentação constante da edição, tendo que reescrever para os instrumentos disponíveis. Outro fator de relevância, principalmente em relação às festas religiosas é a resistência à

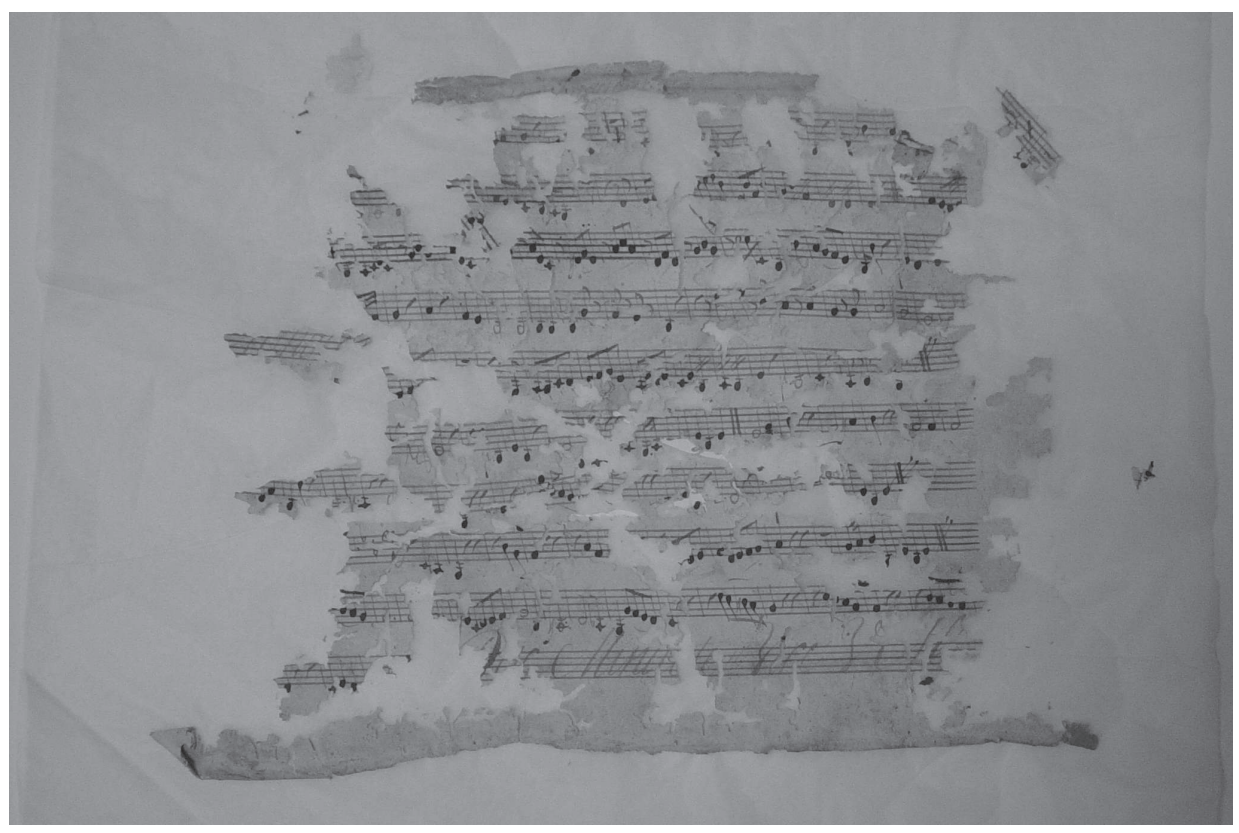

Fig.10 - Documento rendilhado pela ação de cupins. MI-FCLange fragmentos. 


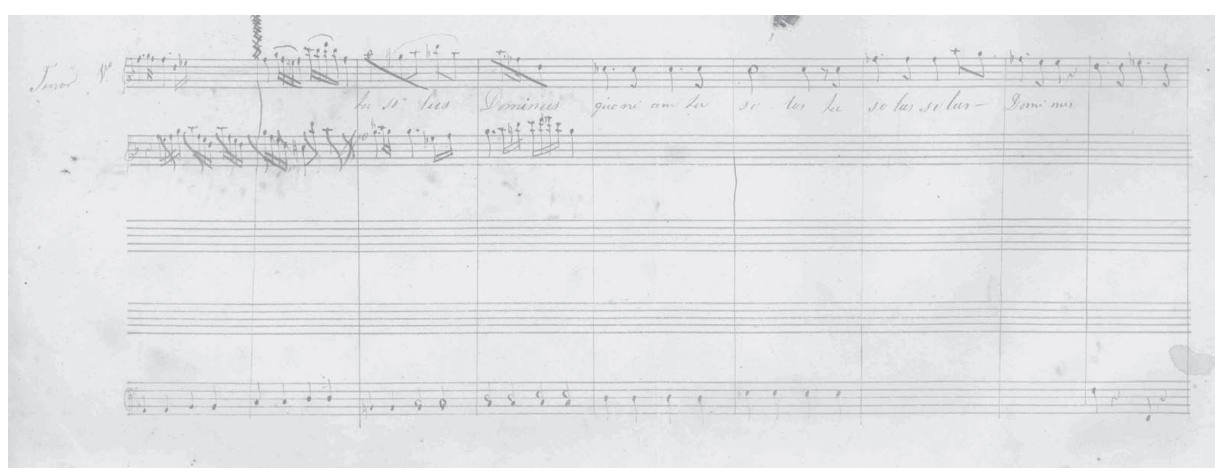

Fig.11 - Manuscrito de trabalho de Anacleto Nunes Maurício Lisboa. MI-FCLange fragmentos.

mudança de um repertório já consagrado pela tradição, mantendo-se assim os papéis antigos e não se utilizando de música impressa, nova.

\section{9 - Arquivos de músicos}

Os manuscritos de trabalho pertenciam exclusivamente ao domínio privado e não saíam da escrivaninha do músico. 0 único documento divulgado era a composição que se deixava para os executantes. Quando recolhemos um arquivo pessoal temos a oportunidade de encontrar os rascunhos, mas quando a recolha é feita em corporações musicais este substrato é quase impossivel de ser visto, uma vez que as obras servem exclusivamente para execução. No acervo de manuscritos musicais do Museu da Inconfidência consta o arquivo pessoal de Anacleto Nunes Maurício Lisboa, ${ }_{12}^{12}$ natural e morador em Vila Rica, músico e escrevente nascido em 1821, parente de João Nunes Maurício Lisboa, nascido em 1772, natural de Vila Rica, também músico e escrevente. Anacleto herdou os papéis de João Nunes; notamos sua marca de posse

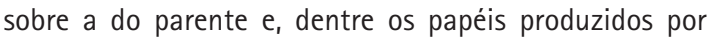
duas gerações de músicos, encontram-se os chamados manuscritos de trabalho. São obras escritas em partitura, e não em partes cavadas, constando todos os erros e correções até chegar ao produto final. Como dissemos anteriormente, esse documentos são preciosos para construir a gênese da obra.

Sobre a transmissão de um arquivo musical, ao analisarmos um lote significativo de testamentos e inventários de músicos que viveram nas cidades de Ouro Preto e Mariana nos séculos XVIII até meados do XIX, notamos que seus papéis não formam o corpus de bens a serem inventariados, somente em alguns raros testamentos existe a menção do arquivo musical sem fazer a relação desses papéis. Diante desses indícios, achamos que o meio mais comum fosse a transmissão direta. Mas existem dois inventários de músicos onde seus papéis foram contestados pelos herdeiros - documentos importantes que mostram a disputa por esses bens.

Em 1819 morre sem deixar testamento Florêncio José
Coutinho, músico e timbaleiro do regimento de milícias de Vila Rica, que, ainda em vida, deixou para João José de Araújo, também músico e companheiro de estante, seus papéis de música. Trata-se de um valioso arquivo com mais de trezentos títulos, sendo metade deles de autoria do próprio Florêncio e o restante de autores brasileiros e europeus, com música sacra, óperas, árias, marchas militares e música instrumental. A posse destes papéis foi contestada em juizo pelas filhas e herdeiras diretas do falecido músico obrigando a recolha e a avaliação dessas obras. A avaliação pode ser observada no inventário de Florêncio José Coutinho, hoje depositado no Arquivo Histórico do Museu da Inconfidência (códice 0054, auto 0644, $1^{\circ}$ ofício), que traz anexa a lista de obras com o valor atribuído a cada uma delas. 0 processo não é conclusivo, não sabemos o caminho que este arquivo tomou, se ficou com as herdeiras, se foi vendido ou se ficou com o amigo Araújo, o fato é que após uma detalhada pesquisa no acervo depositado no Inconfidência, conseguimos identificar alguns desses papéis originais, inclusive, algumas obras citadas no processo com cópia de Araújo. ${ }^{13}$

Outro processo está depositado no arquivo do IPHAN da cidade de São João del Rei (inv. n 128) e trata da disputa dos papéis de música deixados por Lourenço Fernandes Braziel, morto em 1831 sem testamento. 0 litígio era entre seu filho Joaquim Bonifácio Braziel e seu genro João Leocádio do Nascimento, ambos músicos. João Leocádio pleiteava o direito aos papéis, mas o acesso the foi negado por Joaquim Bonifácio. 0 genro pediu que fossem feitas a avaliação e divisão dos papéis, uma vez que dependia das músicas para continuar a trabalhar. No documento consta a lista com cerca de 177 obras do mesmo gênero que aquelas encontradas no acervo de Florêncio Coutinho, além de treze instrumentos musicais. Segundo pesquisas feitas por Aluizio José Viegas, diretor da Orquestra Lira Sanjoanense de São João del Rei, em 1940 o arquivo foi queimado por um dos herdeiros. ${ }^{14}$

Na documentação pertencente ao acervo de Curt Lange 
encontram-se três listas de obras do arquivo pessoal dos músicos Vicente Ferreira do Espírito Santo, Justino da Conceição e Cândido Simplício Marçal, todos ouropretanos atuantes em fins do século XIX início do XX. Estas listas, feitas pelos próprios músicos, foram entregues a Lange pelos seus herdeiros juntamente com os documentos musicais. A partir delas identificamos a origem de cerca de 200 obras do acervo. ${ }^{15}$

\section{0 - Conclusão}

Para melhor compreender os sinais deixados nos documentos seria necessária uma história dos acervos e da sua transmissão. A origem da formação dos fundos possui causas muito diversas: uns reúnem práticas de uma época num determinado local, outros trazem consigo a condição social e os hábitos pessoais do proprietário. As informações recolhidas nos documentos musicais servem para alargar nosso entendimento sobre as práticas musicais, tirando o acervo da condição de simples "ajuntamento" de papéis e sua catalogação focada somente nos aspectos musicais. A possibilidade existe, mas se choca com a fragilidade das condições físicas e funcionais dos arquivos: a fragilidade física, que expõe os documentos às péssimas condições de armazenamento, e falta de formação técnica das pessoas que lidam com o acervo.

Por todo o século XVIII e XIX os músicos copiaram obras a partir de originais autógrafos e destes para novas cópias, expandindo a música para várias regiões brasileiras. A princípio, estes testemunhos paralelos à obra musical parecem sem importância, mas hoje representam elos

para a história da música brasileira, da escrita musical deixada no papel.

\section{Referências}

BELLOTTO, Heloisa Liberalli. Arquivos permanentes - tratamento documental. São Paulo: T. A. Queiroz, 1991.

BIASON, Mary Angela. L'invenzione della stampa musicale. Monografia de final de curso. Istituto per l'Arte ed il Restauro "Palazzo Spinelli", Florença, 1994.

Um autor para o Tantum ergo, CT2 337 - Francisco Manoel da Silva, José Maurício Jr. e António da Silva Leite. In: Anais do XIII Encontro da ANPPOM, Belo Horizonte, 2001, p.355-362.

BLUTEAU, Rapahel, Pe. Vocabulario portuguez Et latino. Coimbra: Collegio das Artes da Companhia de Jesus, 1712 a 1721.

BOUILLET, Marie-Nicolas. Dictionaire des scienses des lettres et des arts. Paris : Hachette, 1908.

BUENO, Francisco da Silveira. Estudos de filologia portuguesa. São Paulo: Saraiva, 1967.

COMBAT, Heitor. "Um 'Magnificat' de J.J. Emerico Lobo de Mesquita (1746-1805)". In: REIS, Sandra Loureiro de Freitas (org.). Il Encontro Nacional de Pesquisa em Música. Belo Horizonte: Imprensa Universitária, 1987, p.67-87.

COPIADOR de algumas cartas particulares do excelentíssimo e reverendissimo senhor dom frei Manoel da Cruz, bispo do Maranhão e Mariana (1739-1762). Museu da Inconfidência, Arquivo Histórico - documentos raros.

CRANMER, David. "Autógrafo ou cópia? Partituras das óperas de Marcos Portugal e Valentino Fioravanti escritas para o Teatro São Carlos". In: Actas do V Encontro nacional de musicologia. Associação portuguesa de educação musical, $n^{\circ}$ 58, 1988, p.27-30.

DUPRAT, Régis. "Metodologia de pesquisa histórico-musical no Brasil". In: Anais de História, Faculdade de Filosofia, Ciências e Letras, Assis, nº 4, 1972, p.101-108.

DUPRAT, Régis e BALTAZAR, Carlos Alberto (org.). Acervo de Manuscritos Musicais: Coleção Francisco Curt Lange. Vol. I, Compositores mineiros. Belo Horizonte: Universidade Federal de Minas Gerais/Museu da Inconfidência, 1991.

DUPRAT, Régis e BIASON, Mary Angela (org.). Acervo de Manuscritos Musicais: Coleção Francisco Curt Lange. Vol III, Compositores anônimos. Belo Horizonte: Universidade Federal de Minas Gerais/Museu da Inconfidência, 2001.

FABRIS, Dinko. "Influenze stilistiche e circulazione manoscritta della musica per liuto in Itália e in Francia nella prima meta del seicento". In: Revue de Musicologie, Sociétè Francaise de Musicologie, Paris, Tome 77 n 02, 1991, p.311-333,.

FRAISSE, Luc. "Le Manuscrit littéraire: son statut, son histoire du Moyen Âge à nos jours". In: GERMAIN, Marie Odete; THIBAULT, Daniele (org). Brouillons d'ecrivains. Paris: Biblioteque Nationale, 2001, p.34-52.

GERMAIN, Marie Odete e THIBAULT, Daniele (org). Brouillons d'ecrivanis. Paris: Biblioteque Nationale, 2001.

GRÉSILLON, Almuth. "Les silences du manuscrit". In: I Encontro de ecdótica e crítica genética, João Pessoa, 1991, p.89-99.

GUILLOT, Laurent. "Les papiers à musique imprimes em France au XVII e siècle - um nouveau critéres d'analyse des manuscrit musicaux". In: Revue de Musicologie, Sociétè Francaise de Musicologie, Paris, Tome 87 n 02, 2001, p.307-325.

HAFFNER, Christel; CADIOT, Anne (org.). Les manuscripts des ecrivains. Paris: Hachette/CNRS, 1993.

HALLEWELL, Laurence. O livro no Brasil. São Paulo: Edusp, 1985.

KERMAN, Joseph. Musicologia. São Paulo: Martins Fontes, 1987.

LE GOFF, Jacques. História e memória. Trad. Bernardo Leitão. Campinas: Editora da Unicamp, 2003.

MASSIP, Catherine. "Les filigranes: utilization, lecture et reproduction". In: Fontes Artis Musicae, Paris, vol. 28/1-2, 1981. 
NASCIMENTO Anna Amélia Vieira. Patriarcado e religião: As enclausuradas clarissas do convento do Desterro da Bahia, 1677-1890, Salvador: Conselho Estadual de Cultura, 1994, p.218-221.

NEEFS, Jacques. "Manuscrits et relation critique". In: I Encontro de ecdótica e crítica genética, João Pessoa, 1991, p.257-268.

PINHO, Ernesto Gonçalves de. Santa Cruz de Coimbra, centro de atividade musical nos séculos XVI e XVII. Lisboa: Fundação Calouste Gulbenkian, 1981.

REZENDE, Maria Conceição. A música na história de Minas Colonial. Belo Horizonte: Itatiaia, 1989

SALLES, Cecilia Almeida. Crítica genética - uma introdução. São Paulo: Educ, 1992.

Mary Angela Biason completou seus estudos musicais na Universidade Estadual Paulista "Júlio de Mesquita Filho", estudou musicologia na Universidade Nova de Lisboa, é Mestre em Artes pela Universidade de São Paulo e doutoranda em Música pela Universidade Estadual de Campinas. Tem-se destacado na organização de acervos de documentos musicais, desenvolvendo trabalhos de organização de arquivos no Museu da Inconfidência em Minas Gerais, no Museu Carlos Gomes em São Paulo, como também a catalogação dos acervos das Bandas do município de Ouro Preto. Entre os vários trabalhos realizados, destacam-se as publicações de catálogos temáticos como forma de garantir o acesso às fontes musicais primárias, e de obras transcritas vocacionadas fundamentalmente para o repertório brasileiro dos séculos XVIII e XIX. Além da musicologia, estudou museologia na Fundação Escola de Sociologia e Política de São Paulo e restauração de papéis no Istituto per l'Arte ed il Restauro "Palazzo Spinelli" em Florença. Atualmente é coordenadora do setor de Musicologia do Museu da Inconfidência. 


\section{Notas}

Outras ocasiões exigiam a contratação de música como funerais e festas particulares, além de entretenimentos populares nos teatros, mas não produziram documentação abundante. A produção conventual foi também considerável, mas conhecemos muito pouco sobre seus acervos administrativos e musicais. 0 trabalho de Ana Amélia Vieira Nascimento sobre o convento do Desterro da Bahia traz algumas informações sobre a prática musical desenvolvida pelas freiras. (NASCIMENTO, 1994, p.218-221).

2 Em 1740, o bispo do Maranhão d. frei Manoel da Cruz envia duas correspondências solicitando repertório para ser executado na Sé em São Luiz: uma à Santa Igreja Patriarcal de Lisboa e outra à abadessa do convento de Odivelas (COPIADOR de algumas cartas afls. 7v e 9v). Em 1741, o bispo do Rio de Janeiro d. João da Cruz recebe carta do mestre de capela Caetano de Santa Rosa listando obras de Palestrina, Orlando de Lassus, Alessandro Scarlatti, Lully, Rameau, Frescobaldi, Monteverdi e Pergolesi (REZENDE, 1989, p.220). Em 1788 o bispo de Minas Gerais, d. frei Domingos da Encarnação Pontevel recebe uma remessa de Portugal com 18 músicas de diversos autores, entre eles Joseph Haydn e Michael Haydn (COMBAT, 1985, p.73).

3 Veja autores como: CARDOSO, André. 8 Lição para as Matinas de Quarta-Feira Santa:Uma Atribuiccão de Autoria entre Jerônimo de Souza Lobo e José Joaquim Emerico Lobo de Mesquita. Dissertação de Mestrado, UNIRIO, 1996; DOTTORI, Maurício. Ensaio sobre a música colonial mineira. Dissertação de Mestrado, ECA-USP São Paulo, 1992; e CRESPO FILHO, Silvio Augusto. Contribuição ao estudo da caracterização da música em Minas Gerais no Século XVIII. Tese de Doutorado. ECA-USP, São Paulo, 1989. Somente para citar alguns.

4 Disciplina criada em Paris no final da década de 1960, quando a Biblioteca Nacional da França contratou um grupo de germanistas para pesquisar os manuscritos do poeta romântico Henrich Heine. Após grande discussão a solução encontrada foi estudar o processo de criação do texto literário, a partir de procedimentos estruturalistas.

5 Para saber mais sobre o assunto ver: SALLES, Cecilia de Almeida; CARDOSO, Daniel Ribeiro. "Crítica genética em expansão". In: Ciência e Cultura, jan./mar. 2007, vol.59, nº1, p.44-47.

6 Fraisse faz a análise a partir de vocabulários franceses e espanhóis dos séculos XVI, XVII e XVIII. Da nossa parte, conferimos no dicionário de português do início do século XVIII escrito pelo Pe. Rafael Bluteau, de onde recolhemos os seguintes verbetes: "AUTOR: aquele que dá principio a alguma coisa, o instituidor ou executor dela"; "ESCRITOR: autor de algum livro"; "IMPRESSÃO: a arte de imprimir livros. (...) A impressão de um livro (falando na ação dos impressores que atualmente estão trabalhando) não acho palavra mais própria do que impressio, se se falar na ação de dar o livro à estampa e à luz pública, o que se pode assim do autor como do impressor". No verbete "escrever", Bluteau dá a definição de Cícero, que é compor.

7 Um trabalho desse gênero pode ser conferido em: FIGUEIREDO, Carlos Alberto. Editar José Maurício Nunes Garcia. Tese de Doutorado. Centro de Letras e Artes, UniRio, Rio de Janeiro, 2000.

8 Página de rosto de um Credo sem indicação de autor, Museu da Inconfidência - Coleção Francisco Curt Lange no 409.0 primeiro nome citado, Leandro Lopes de Oliveira, nasceu em Vila Rica no ano de 1800, filho natural de Marcos Coelho Neto com a crioula forra, Maria Lopes de Oliveira.

9 Todos os textos citados neste item encontram-se nas partes instrumentais e vocais das obras que compõem a Coleção Francisco Curt Lange, depositada no Museu da Inconfidência.

10 Sobre o histórico da indústria papeleira portuguesa ver MELO, Arnaldo Faria de Ataide e. 0 papel como elemento de identificação. Lisboa: Biblioteca Nacional, 1926.

11 Conjunto de cilindros acionados pela força dos ventos, que batem alternadamente na formação da pasta de papel, feita a partir de trapos de tecido.

12 Estes documentos estão espalhados dentro da Coleção Francisco Curt Lange.

130 documento em questão foi analisado por Cássio Lanari e reproduzido no trabalho não publicado de Tarquínio José Barbosa de Oliveira. A Música Oficial em Vila Rica. [197?: datilo], p.105-109.

14 Uma análise completa do documento encontra-se nesta tese: RICCIARDI, Rubens Russomano. Manoel Dias de Oliveira: um compositor brasileiro dos tempos coloniais - documentos e partituras. Tese de Doutorado. Escola de Comunicação e Arte-USP, São Paulo, 2000, p.73-84.

15 Projeto de pesquisa apresentado para o Plano de Ação 2001: MinC / IPHAN - Museu da Inconfidência e concluído em 2002. A listagem encontra-se no setor de Musicologia do Museu. 